\title{
D-Glyceric Aciduria
}

National Cancer Institute

\section{Source}

National Cancer Institute. D-Glyceric Aciduria. NCI Thesaurus. Code C128804.

An autosomal recessive genetic disorder caused by mutations in the GLYCT K gene,

encoding glycerate kinase. The condition is characterized by excretion of D-glyceric acid

in the urine. The phenotype varies from mild to severe, and may result in encephalopathy,

mental retardation, microcephaly and early death. 